\title{
$\begin{array}{lllllllll}\mathrm{I} & \mathrm{N} & \mathrm{S} & \mathrm{T} & \mathrm{I} & \mathrm{T} & \mathrm{U} & \mathrm{T} & \mathrm{E}\end{array}$
}

\section{Age and Lifecycle Patterns Driving U.S. Migration Shifts}

\author{
KENNETH M. JOHNSON, RICHELLE WINKLER, LUKE T. ROGERS
}

$\mathrm{M}$ igration-people moving between locations-is now driving much of the demographic change occurring in the United States. Over time, the ebb and flow of migration alters the size, age, and sex composition of local populations. The propensity to migrate varies by age, with young adults the most likely to migrate. Here we summarize new research using recently developed county-level age-specific net migration estimates that identify distinct migration signatures for urban and rural counties. Signatures are unique age-specific net migration patterns that can be used to classify county types. The data provide evidence of spatial clustering in the age-specific migration patterns in large geographically contiguous areas, such that migration patterns are changing the age structure of entire regions. ${ }^{1}$ Such migration patterns have important implications for people, institutions, and communities of both rural and urban America, as well as for the design of policies and practices that foster the development of sustainable communities. ${ }^{2}$

\section{Migration Tells Different Stories in Different Places}

Our analysis of trends over time shows clear evidence that certain age groups migrate in similar ways. Here, we examine migration for four age groups evident in the data representing different stages of the life cycle. ${ }^{3}$ The four groups are: emerging adults, young adults, family age, and older adults. The first two age groups are the most mobile part of the population (see Box 1).

To illustrate the different migration patterns among these age groups, we compare simplified migration signatures for four different county types. The first includes the 65 core counties of large metropolitan areas with more than a million residents. These core counties contain the largest city in the metropolitan area together with some older inner suburbs. Some 90.2 million people (29.5 percent of the U.S. total) resided in these large core counties in 2010. These counties, such as Cook (Chicago), Suffolk (Boston), and Milwaukee, are extremely attractive to young adult migrants and also attract emerging adults, but they lose migrants in the family and older age groups (see Figure 1).

\section{Key Findings \\ - Young adult migrants are flowing to large metropolitan cores. \\ - Family age migrants are leaving large urban cores for the suburbs. \\ - Major metro areas in the Northeast and Midwest are losing older migrants. \\ Rural farm counties continue to lose young adults.}

Box 1. Migration Age Groups

Emerging adults (age 15 to 24)-Migration for this group is stimulated by the transition from parental households to independent living, such as the movement to college, the military, or first jobs. Immigrants also contribute to migration among this age group.

Young adults (age 25 to 29)-Migration for young adults often reflects the completion of education or training and the transition to full time, career-oriented employment.

Family age (children age 5 to 14 and adults age 30 to 49)-Migration for these adults and their dependent children generally reflects a life-cycle transition from independent living to family life associated with marriage, children, and home purchases.

Older adults (including those age 50 to 74 ) Although older adults are the least mobile of these age groups, they tend to migrate to locations rich in scenic and built amenities or to relocate in proximity to their own adult children. 
Figure 1. NeT MIGRATION TRENDS FOR SELECTED METROPOLITAN AND NONMETROPOLITAN COUNTIES, 2000 TO 2010

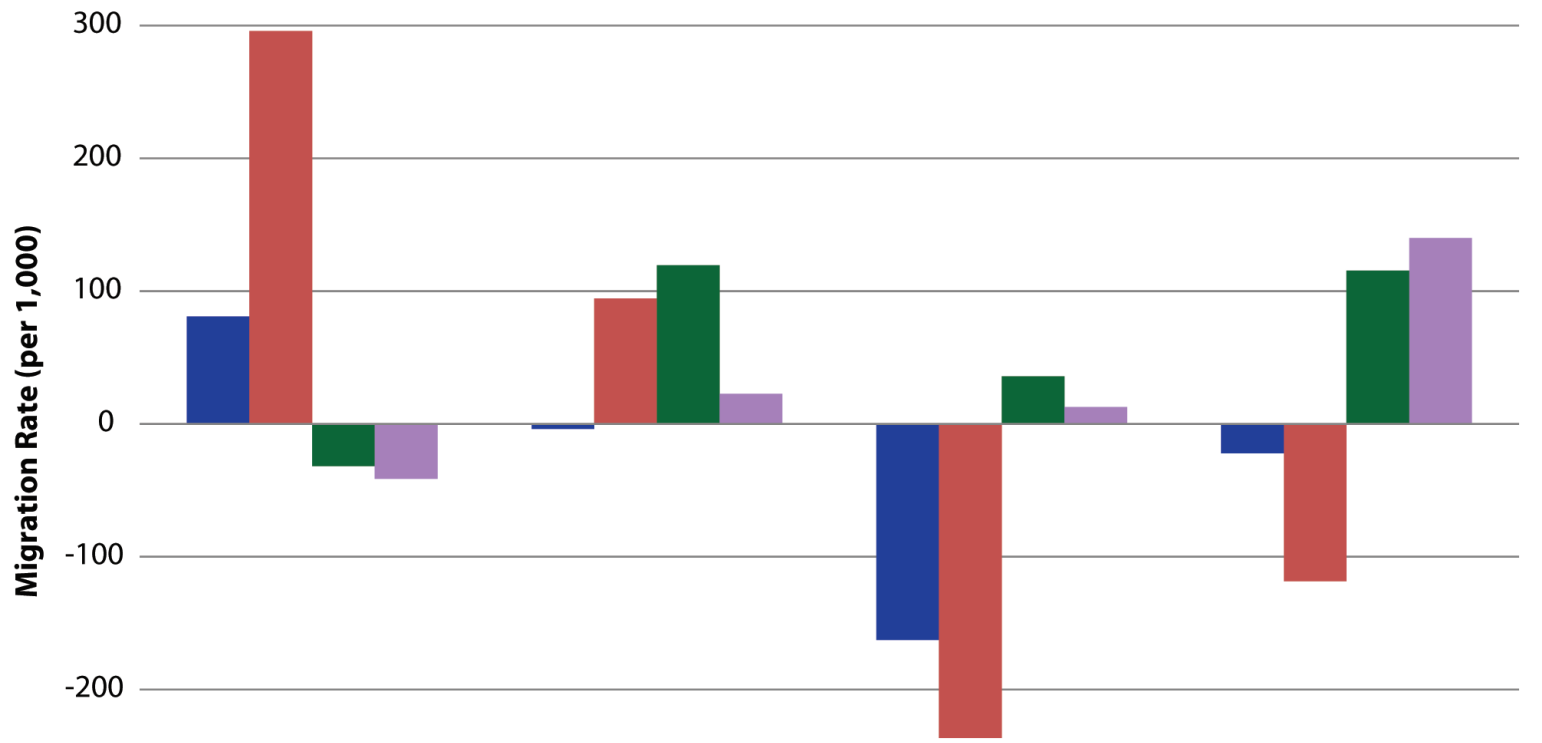

$-300$

Large Metro Core Large Metro Non-Core Non-Metro Farm Non-Metro Recreation

Source: Winkler et al., 2013

Analysis: K.M. Johnson, UNH

Emerging Adults $\square$ Young Adults $\square$ Family Age $\quad$ Older

In the 349 non-core counties that surround the large urban cores, migration patterns are strikingly different. Nearly 74 million people representing the bulk of the suburban population of large metropolitan areas reside in these counties. Here migration gains are greatest for the family age population, who are attracted to larger homes, open space, and quality $\mathrm{K}-12$ education districts perceived to be conducive to childrearing. Such family age migrants are also attracted to the large concentration of employment opportunities in such suburban areas. These suburban areas also attract young adults, but they experience a migration loss among the emerging adult age group. There is also a modest inflow of retirement age adults to non-core counties.

A detailed look at the age-specific migration patterns illustrate the complementarity of the migration signatures of large urban core and suburban counties and show how the impact of life-cycle factors influences these migration signatures. The social, lifestyle, and economic opportunities of the urban core counties attract large streams of young and emerging adults to them (see Figure 2). However, the cores are less attractive to family age population as illustrated by the widespread net migration loss among all age groups over the age of 35 as well as among children. In contrast, the non-core suburban counties migration signature reflects a large net inflow of adults in their thirties and forties and of children, underscoring their appeal to family age populations (see Figure 3 ). These suburban counties do tend to lose emerging adults as is evident from the net migration loss for this group from 2000 to 2010. The actual numerical gains and losses are quite substantial. For example, large urban core counties had a net migration gain of 2.7 million young and emerging adults between 2000 and 2010, but a net migration loss of 1.4 million family age individuals. In contrast, suburban counties of large metropolitan areas had a net migration gain of 3.9 million family age residents, but just 400,000 young adults.

Migration patterns in rural areas differ in significant ways from those in urban areas. Researchers tracking nonmetropolitan population redistribution have long recognized that there are significant differences among rural counties. Here we consider two distinctly different types of rural counties: those dependent on agriculture which have long histories of outmigration and those rich in scenic and recreational amenities that have sustained histories of substantial migration gain. ${ }^{4}$ The 403 agricultural counties represent the most traditional element of nonmetropolitan America. They included just 3 million residents in 2010. Age-specific migration losses for agricultural counties were greatest for emerging and young adults. The sustained loss of young people from farm counties has long been a significant policy concern because it represents a loss of human resources and diminishes the potential for future growth. Farm counties had modest gains of family age population and a small inflow of older adults. These modest gains were not sufficient to offset the loss of young adults. 
Figure 2. Migration SIgNATURES FOR LARgE URBAN CORE COUNTIES, 1980 TO 2010

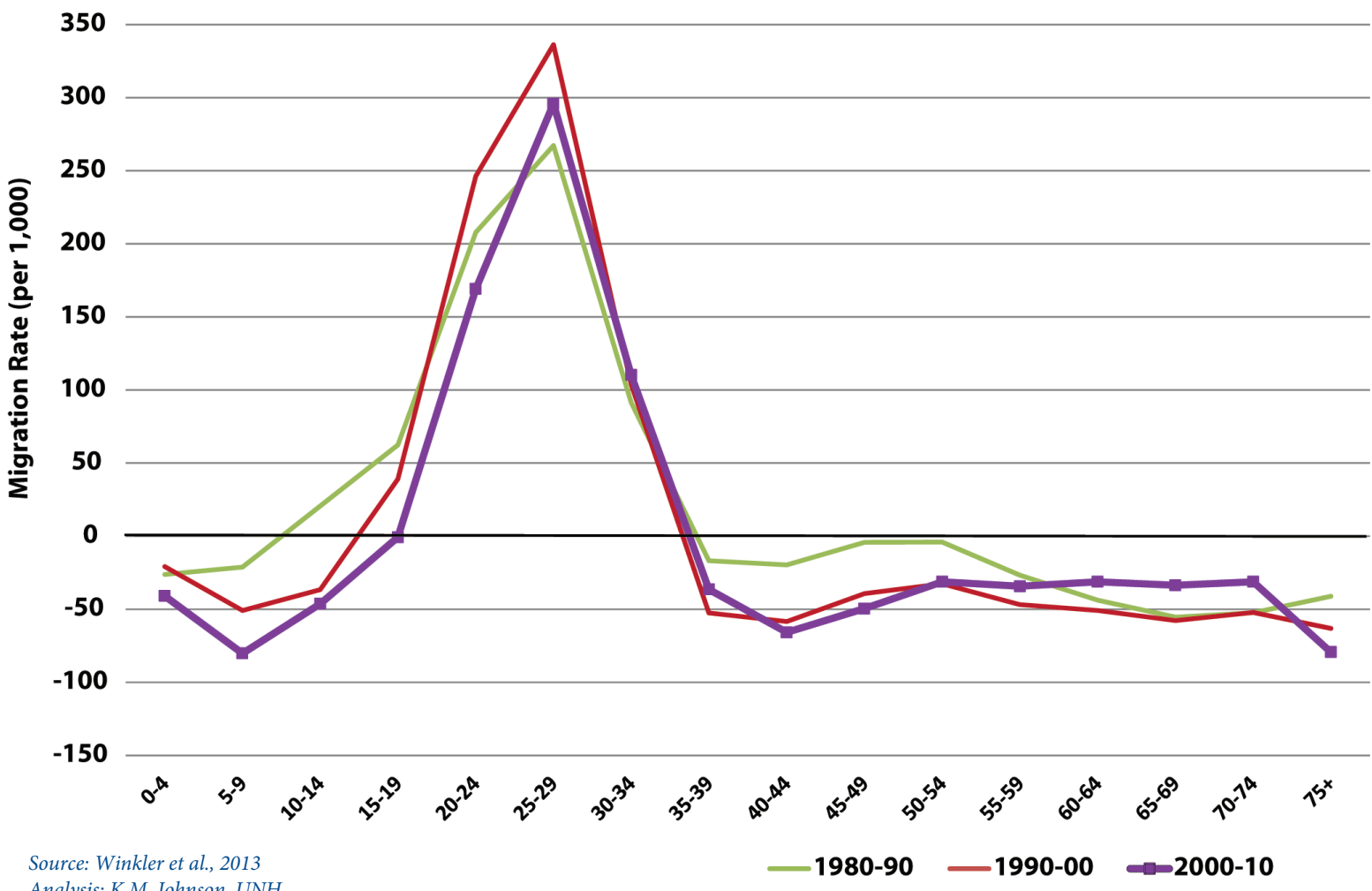

Figure 3. Migration SignAtURES FOR LARge URbAN NON-CORE COUNTIES, 1980 TO 2010

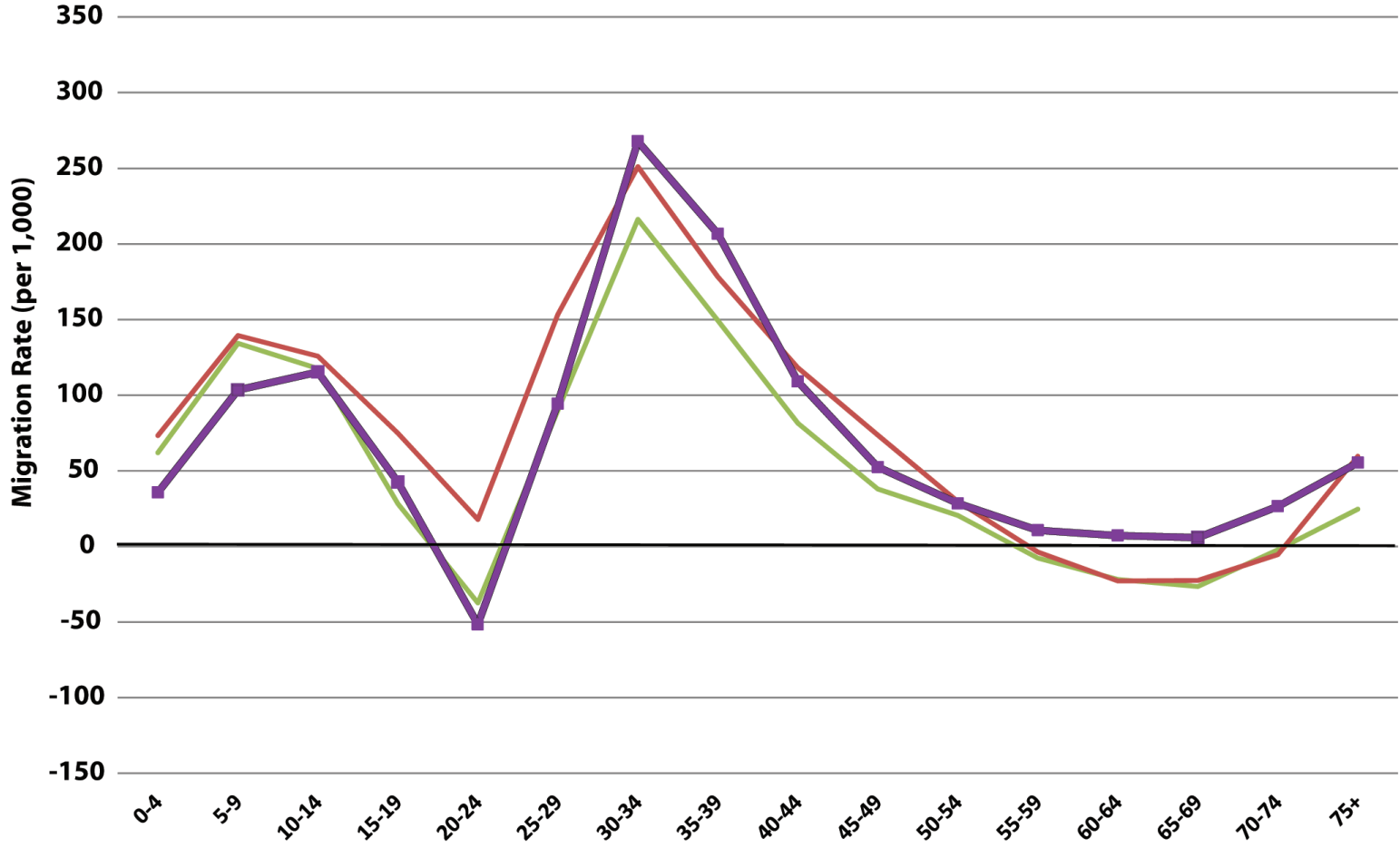




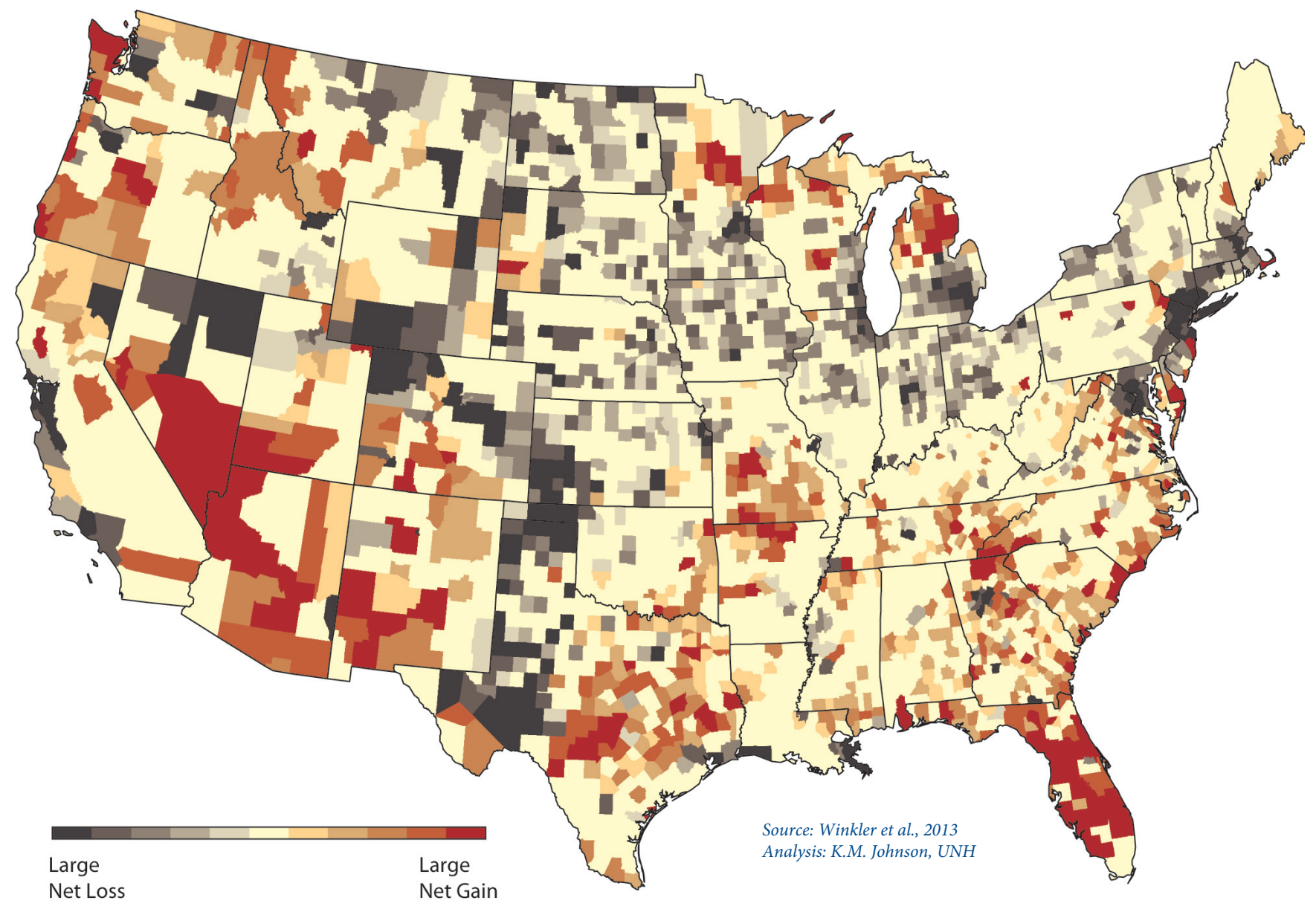

If farm dependent counties are the most traditional of nonmetropolitan counties, then recreational counties represent the most contemporary group. The 299 nonmetropolitan recreational counties included 8.2 million residents in 2010 and are among the fastest growing nonmetropolitan counties. Most of their population increase has been fueled by migration. ${ }^{5}$ Recreational counties are particularly attractive to older migrants, but they also appeal to a family age population. Migration losses did accrue among emerging adults and young adults, but even these were modest compared to those in farm counties. The fact that recreational counties also attract family age migrants is an important but often overlooked point. Family age populations are likely to be attracted by the economic and employment opportunities occasioned by the influx of often affluent older adults and/ or the natural and built amenities in the area. ${ }^{6}$ The continuing influx of retirement age adults to recreational counties has significant implications given that the ranks of those in their 50s and 60s are already swelling as the 70 million baby boomers continue to age.

\section{Spatial Patterns of Age-Specific Migration}

The research summarized here found clear evidence of spatially distinct patterns of migration for each of the four age groups considered. To illustrate this, we consider the spatial patterns for those 50-74 (see Figure 4). Recreational areas in Florida and coastal areas of the Southeast attracted older migrants, as did the foothills of the Ozarks and the Great Smokey Mountains. Lake areas in the Upper Great Lakes also emerge as in-migration hotspots for older adults. In the West, Arizona, New Mexico and parts of the Northwest and Intermountain region also attracted older adults. In contrast, virtually the entire urban agglomeration stretching from Boston to Washington exhibits substantial rates of out-migration among older adults. Similar patterns are evident in the urban regions centered on Minneapolis, Chicago, Detroit, and Cleveland. In the West, Los Angeles and San Francisco emerge as hotspots of net out-migration 
for older adults. And there are scattered clusters of older adult out-migration in the Great Plains. These spatial clusterings illustrate the stark contrast between the large metropolitan areas that attracted younger adults and family age population, and the amenity areas that are attracting older adults. These differential patterns underscore the importance of the life cycle to migration and have significant policy implications given the large numbers of baby boomers now beginning to disengage from the labor force. The opposing migration patterns of emerging and young adults with those of older adults together fuel the aging of rural America and maintain a relatively young age structure in large metro areas and especially in core counties.

\section{Conclusion}

This brief illustrates how recently released, age-specific net migration estimates contribute to a fuller understanding of the complex patterns of demographic change in the country. Migration is now a driving force underlying population redistribution in the United States. Analysis of age-specific migration data identified four empirically distinct migration groups that produced differing migration signatures for several types of urban and rural counties. Our research also illustrates the geographic variation in the patterns of migration growth and decline for one of our four age clusters. Such spatial and county type variation manifests the impact of life cycle changes on the propensity to migrate. The analysis summarized here hints at the significant contribution these new, publically available data can make to research and policy analysis. These migration estimates give contemporary researchers the tools they need to investigate how migration is reshaping the nation and provide planners and policy makers with the information they need to consider how such migration change will influence the people, institutions and communities of both rural and urban America. The data are available to the public for download and interactive mapping and chart-building at www.netmigration.wisc.edu.

\section{Support}

The research summarized in this brief was supported by the National Institutes of Health, Eunice Kennedy Shriver Center of Child Health and Human Development (Grant Number 7R03HD069737-02). Additional support was provided by the U.S. Department of Agriculture, Economic Research Service, Joint Agreement 58-60000-0-0055. The content is solely the responsibility of the authors and does not necessarily represent the views of the Eunice Kennedy Shriver National Institute of Child Health and Development, the National Institutes of Health, or the United States Department of Agriculture.

\section{E N D N O T E S}

1. This paper summarizes research presented in K.M. Johnson, R. Winkler, and C. Cheng, "Migration Signatures through the Decades: Continuity and Change in Age-Specific Net Migration in U.S. Counties." Paper presented at the Annual Meetings of the Population Association of America, New Orleans, LA, April 11, 2013. Methodological issues are discussed in: "R.L. Winkler et al., "County-specific Net Migration by five-year age groups, Hispanic Origin, Race, and Sex 2000-2010," CDE Working Paper No. 2013-04, 2013, Center for Demography and Ecology, University of Wisconsin-Madison, Madison, WI.

2. The dataset used for this analysis contains age-specific net migration data for every U.S. county by Hispanic origin, race, and sex. It is available to the public without charge and includes a suite of graphic and mapping applications to facilitate the work of researchers, planners, and policy makers who need to understand local migration patterns. The data and analytical tools are available at: http://www.netmigration. wisc.edu.

3. For details of the empirical analysis, See Johnson, Winkler, and Cheng, "Migration Signatures through the Decades."

4. K.M. Johnson, "Rural Demographic Change in the New Century," Issue Brief No. 44 (Durham, NH: Carsey Institute, University of New Hampshire, 2012), 1-12.

5. Ibid.

6. K.M. Johnson and S.I. Stewart, "Amenity Migration to Urban Proximate Counties," G. P. Green, D. Marcouiller, and S. Deller (eds.), Amenities and Rural Development: Theory, Methods and Public Policy (Cheltenham, UK: Edward Elgar Publishing, 2005), 177-196.

7. J. Cromartie, and P. Nelson, Baby Boom Migration and Its Impact on Rural America (Washington, DC: U.S. Department of Agriculture, Economic Research Service, 2009) ERR-79. 


\section{A B OUT THE AUTHORS}

Kenneth M. Johnson is the senior demographer at the Carsey Institute and professor of sociology at the University of New Hampshire (ken.johnson@unh.edu).

Richelle Winkler is an assistant professor of sociology and demography at Michigan Technological University (rwinkler@mtu.edu).

Luke T. Rogers is a research assistant at the Carsey Institute and a doctoral candidate in sociology at the University of New Hampshire.

\section{A C K N O W L E D G E M E N T S}

Research assistance was provided by Barb Cook of the Carsey Institute and by Cheng Cheng at Princeton University. Thanks to Curt Grimm, Laurel Lloyd, and Amy Sterndale at the Carsey Institute for their helpful comments and suggestions.

\section{A UNIVERSITY mi. of NEW HAMPSHIRE}

\section{CARSEY}

Building knowledge for families and communities

The Carsey Institute conducts policy research on vulnerable children, youth, and families and on sustainable community development. We give policy makers and practitioners timely, independent resources to effect change in their communities.

This work was supported by the National Institutes of Health and the U.S. Department of Agriculture.

Huddleston Hall

73 Main Street

Durham, NH 03824

(603) $862-2821$

www.carseyinstitute.unh.edu 